\title{
Ciências da Natureza na Educação do Campo: encontros e desencontros na luta pela Educação Popular
}

\author{
Wender Faleiro ${ }^{1}$ Gustavo Cunha de Araújo $^{2}$, Cícero da Silva ${ }^{3}$ \\ ${ }^{1}$ Universidade Federal de Goiás - UFG. Regional Catalão. Programa de Pós-Graduação em Educação. Av. Dr. \\ Lamartine Pinto de Avelar, 1120. Setor Universitário. Catalão - GO. Brasil. wender.faleiro@gmail.com. \\ ${ }^{2}$ Universidade Federal do Tocantins - UFT. ${ }^{3}$ Universidade Federal do Tocantins - UFT.
}

A Revista Brasileira de Educação do Campo - RBEC, ISSN 2525-4863, periódico do Departamento de Educação do Campo, da Universidade Federal do Tocantins, campus de Tocantinópolis, acaba de lançar seu primeiro dossiê temático "Ciências da Natureza na Educação do Campo: encontros e desencontros na luta pela Educação Popular" com 8 artigos científicos recebidos no período de submissão (de abril de 2017 a julho de 2017). Este dossiê nasceu da união da Revista ao Congresso Nacional de Ensino de Ciências e Formação de Professores, promovido pelo Grupo de Estudos, Pesquisa e Extensão em Ensino de Ciências e Formação de Professores - GEPEEC/UFG, Regional Catalão, estado de Goiás.

O dossiê reúne trabalhos que discutem fundamentos sociais, históricos, políticos, culturais, filosóficos, pedagógicos e psicopedagógicos das Ciências da Natureza na Educação do Campo no Brasil, explorando as relações entre a dimensão da formação de professores, sujeitos e práticas de ensino em espaços escolares e não escolares, conhecimento, cultura e desigualdades educacionais. Logo, compreender e difundir a Educação do Campo e, em especial, sua habilitação em Ciências da Natureza, nos diversos setores e níveis educacionais com a proposição de ações efetivas de enfrentamento de seus desafios, constitui-se num passo importante e necessário à valorização da Educação do Campo e a possibilidade da garantia do exercício pleno de direitos pelos povos camponeses.

A área de Ciências da Natureza na Educação do Campo demostra que está crescendo e se fortalecendo como área produtiva e que contribui para o desenvolvimento educacional no contexto do campo, como revelam a pesquisas relatadas nos artigos deste Dossiê. São 8 artigos provenientes de diferentes universidades das cinco regiões do Brasil, a saber: 01 artigo da região Norte (Universidade Federal do Pará - UFPA/Universidade do Vale do Taquari UNIVATES), 02 oriundos da região Centro-Oeste (Instituto Federal de Mato Grosso - IFMT e Universidade Federal de Goiás - UFG), 01 artigo proveniente da região Nordeste (Universidade Federal da Bahia - UFBA/Universidade Estadual de Santa Cruz - UESC), 01 da região Sudeste (Universidade Federal do Triângulo Mineiro - UFTM) e 03 artigos oriundos da região Sul (Universidade Federal do Pampa - UNIPAMPA/Universidade Federal do Rio Grande do Sul - UFRGS, Universidade Federal da Fronteira Sul - UFFS e Universidade Federal de Santa Catarina - UFSC).

Abrimos a apresentação dos artigos no dossiê com o trabalho intitulado "Interculturalidade e conhecimento tradicional sobre a Lua na formação de professores no/do campo", de autoria de Rodrigo dos Santos Crepalde, Verônica Klepka e Tânia Halley Oliveira Pinto (UFTM). Os pesquisadores abordam a formação de professores para a Educação do Campo em diálogo com a interculturalidade que, segundo os mesmos, entendem 
que o ensino de ciências deve considerar a cultura na formação de docentes para o campo, contribuindo para o intercâmbio e produção de conhecimento.

Já no artigo intitulado "Uso de objetos educacionais digitais para ensinar sistemas do corpo humano em uma escola do campo", dos pesquisadores Marcelo Franco Leão e Silvio Ferreira dos Santos (IFMT/UFRGS), a atenção está sobre a utilização da tecnologia voltada ao processo de ensino e aprendizagem. Nesse estudo, analisa-se a utilização de softwares educacionais com o objetivo de ensinar sistemas do corpo humano, numa escola do campo, em Mato Grosso. Com base nos resultados dessa pesquisa, os autores relataram que a utilização de tecnologias digitais pelos estudantes permitiu que os mesmos aprendessem melhor os conteúdos relacionados aos sistemas do corpo humano, em comparação com recursos tradicionais, como o livro didático, por exemplo.

Agrotóxicos no campo é o tema do artigo "Discutindo a temática agrotóxicos relacionada à saúde: uma abordagem através das controvérsias sociocientíficas", de autoria de Eril Medeiros da Fonseca, Leandro Duso e Marilisa Bialvo Hoffmann (UNIPAMPA/UFRGS). O artigo discute as implicações dos agrotóxicos para a saúde da população camponesa, por meio da abordagem das Controvérsias Sociocientíficas (CSC) no Ensino de Ciências e na Educação do Campo. Nesse sentido, afirmam que além de prejudicar a saúde daquelas pessoas que vivem e trabalham no campo, os agrotóxicos trazem uma concepção de saúde que afeta a diversidade biológica.

No manuscrito intitulado "Júri Simulado e tempestade cerebral: entendendo a implantação da Usina Hidrelétrica de Belo Monte", de autoria de Marcos Marques Formigosa, Marli Terezinha Quartieri e José Cláudio Del Pino (UFPA/UNIVATES), a partir das estratégias metodológicas do Júri Simulado e Tempestade Cerebral, discutem as metodologias utilizadas por professores que ensinam conteúdos de Física por meios tradicionais. Nessa investigação, identificaram que essas metodologias - Júri Simulado e Tempestade Cerebral - contribuíram para que os conteúdos do ensino de Física fossem ampliados aos estudantes, além de terem possibilitado aos discentes um entendimento crítico da realidade da qual fazem parte.

$\mathrm{O}$ artigo intitulado "A sustentabilidade, a educação ambiental e o curso de Educação do Campo: é possível essa aproximação?”, das pesquisadoras Juliana Pereira Araújo, Maria Paulina de Assis e Elis Regina Costa (UFG), tem como base reflexões sobre formação de professores no curso de Licenciatura em Educação do Campo com habilitação em Ciências da Natureza, da UFG - Regional Catalão. Ao discutirem desafios para consolidação dessa licenciatura, as autoras apontam a necessidade de estabelecer compreensão sobre sustentabilidade como a avaliação das possibilidades de sua utilização como norteador da prática ou inspiração teórico-metodológica. Os resultados da pesquisa revelaram que o conceito de sustentabilidade é mais complexo do que parece, exigindo maior compreensão por parte dos docentes e estudantes.

Em "Formação de professores em Ciências da Natureza para escolas do/no campo na UFFS - Campus Erechim: perspectivas e desafios", de autoria de Moises Marques Prsybyciem, Almir Paulo dos Santos e Jeronimo Sartori (UFFS), o objetivo proposto é evidenciar, no processo de formação de professores, perspectivas e desafios no Curso Interdisciplinar em Educação do Campo: Ciências da Natureza (Licenciatura da UFFS, Campus Erechim), para escolas do/no campo. Com base nos resultados, os pesquisadores afirmam que ficaram evidentes desafios e potencialidades na formação de professores para as escolas localizadas nas comunidades indígenas e nas escolas do/no campo, assim como a necessidade de sua articulação com o Ensino de Ciências da Natureza (Química, Física e Biologia), tais como: a identidade cultural dos sujeitos, o choque de culturas (diferentes povos do campo e diferentes especificidades), os aspectos pedagógicos relacionados à organização e ao trabalho no regime de alternância. 
No penúltimo artigo, "Fenômenos como mediadores do processo educativo em Ciências da Natureza e Matemática na Educação do Campo", elaborado pelos pesquisadores Marcelo Gules Borges, Juliano Espezim Soares Faria e Elizandro Maurício Brick (UFSC), o propósito é analisar uma prática pedagógica desenvolvida na Licenciatura Educação do Campo da UFSC a fim de discutir e destacar os modos pelos quais os fenômenos podem ser potentes para o Ensino das Ciências da Natureza e Matemática. Com base na experiência pedagógica desenvolvida nessa Licenciatura, os autores analisaram as estratégias tomadas e caminhos trilhados na elaboração de estudos de conhecimentos específicos das Ciências da Natureza e Matemática na delimitação da dimensão natural de fenômenos socialmente relevantes no contexto de origem dos estudantes. A pesquisa mostrou que trabalhar com fenômenos é uma dentre várias possibilidades de organização da docência e do conhecimento na formação de professores.

Por fim, apresentamos o último artigo: "Ciências da Natureza na Educação do Campo: em defesa de uma abordagem sócio-histórica", que é fruto de uma pesquisa realizada por Edilson Fortuna de Moradillo, Hélio da Silva Messeder Neto e Elisa Prestes Massena (UFBA/UESC) cujo foco é a defesa da abordagem sócio-histórica nos cursos de formação de professores para atuar na área das Ciências da Natureza da Licenciatura em Educação do Campo. Nesse trabalho, os pesquisadores defendem os referenciais do materialismo histórico-dialético, do Sistema de Complexos de Pistrak, da Pedagogia Histórico-Crítica e da Psicologia Histórico-Cultural como os norteadores dessa abordagem, tendo em vista a categoria trabalho como fundante do ser social, o eixo condutor. Os pesquisadores defendem que a abordagem sócio-histórica possibilita trabalharmos a perspectiva historicizadora de homem e da realidade social, permitindo avançarmos no sentido da luta contra hegemônica na educação e na sociedade na busca da emancipação humana.

Esperamos que esse dossiê seja útil e transformador!

Como citar este editorial / How to cite this editorial

APA:

Faleiro, W., Araújo, G. C., \& Silva, C. (2017). Ciências da Natureza na Educação do Campo: encontros e desencontros na luta pela Educação Popular. Rev. Bras. Educ. Camp., 2(3), 833-835.

ABNT:

FALEIRO, W.; ARAÚJO, G. C.; SILVA, C. Ciências da Natureza na Educação do Campo: encontros e desencontros na luta pela Educação Popular. Rev. Bras. Educ. Camp., Tocantinópolis, v. 2, n. 3, p. 833-835, 2017.

\section{Orcid}

Wender Faleiro

iD http://orcid.org/0000-0001-6419-296X

Gustavo Cunha de Araújo

https://orcid.org/0000-0002-1996-5959

Cícero da Silva

https://orcid.org/0000-0001-6071-6711

\begin{tabular}{|l|l|l|l|l|l|l|l|}
\hline Rev. Bras. Educ. Camp. & Tocantinópolis & v. 2 & n. 3 & p. $833-835$ & jul./dez. & 2017 & ISSN: 2525-4863 \\
\hline
\end{tabular}

